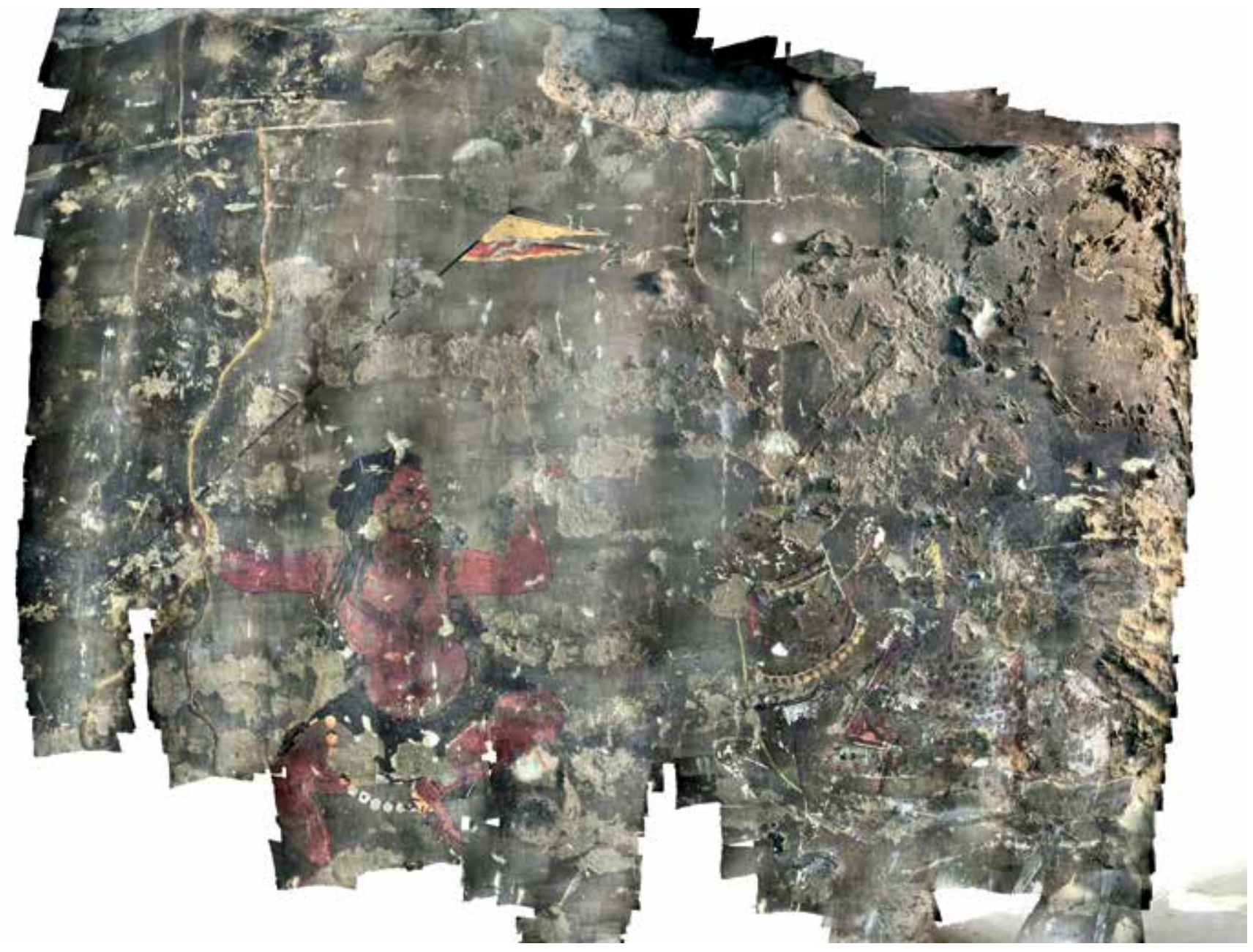

The mural as found in the wall at the southwest corner of the Mohan Chowk, Hanumandhoka Durbar. 


\title{
A MURAL AT THE SOUTHWEST CORNER OF THE MOHAN CHOWK: PIECE OF HISTORY - REDISCOVERED
}

\author{
Madan Chitrakar \\ Principal, Sirjana College of Fine Arts
}

\begin{abstract}
During the restoration process, the experts from JAICA, made a chance discovery of a mural. But unfortunately, its viewing was/is almost totally blocked by an extra wall, built right in-front of the actual wall, with the murals. To demystify the contents, it has had remained a professional challenge, as it could be barely viewed by one end only - from within a space between 8-9 inches gap.
\end{abstract}

It posed challenge for many reasons. First was its difficult location. Secondly, the painted wall was also damaged beyond descriptions - plaster-surface peeled off spread all over - making the task to read the images even harder. Most importantly, to read the contents or to identify the imageries in such a location, it asked for a professional ability of an art writer or an art historian, to be able to read and analyze. However, after a very meticulous effort and a proper reading of the postures, emblems and other iconographical features, the narratives are being made explaining on and about the murals found.

The essay is prepared and is made, after a series of exercises - begun by field visits, and followed by closer examination of the images on the spot and as is available in digital images. The writing is made - after the long afterthoughts, and in consultation with the available references.

\section{Keywords: Hanumandhoka Palace, Kapalika, mural, plaster-surface}




\section{Background}

Like many other monuments, Hanumandhoka Palace Complex suffered some major damages, aftermath of the Great Quake of 2015). As part of Government of Nepal's initiative to save the monument, experts from JAICA, Japan were invited. And accordingly, in the process, some murals discovered by chance, remained unexplored and unexplained. The following lines seek to explain on and about the untold mural.

\section{Introduction}

A hidden part of an interior wall - with an exquisite mural painting, located at the first floor of 'Agam-chhen', Hanumandhoka Palace Complex, has had been in wait for centuries - to be re-discovered; and explained. Dimly lit, the area could have easily passed as inconsequential and of little significance, except to a few informed. Inconveniently located and so badly damaged, in a normal time and situation, the mural would have been completely lost to obscurity and easily being forgotten. However, this is until the recent findings - a brilliant chance - discovery made by a team of conservation experts from Japan who also, insisted upon its importance and remained keen to be explored. And this has provided reasons to explore more.

\section{The Challenges}

But the task also posed challenges. The first and the major, is being the unusually very difficult location of the entire mural-wall: to be able to view and read it firsthand. The entire wall with the mural is totally blocked by another second new wall - top to the bottom, right in the front, leaving an open gap of - hardly five inches between the two walls. Apparently the frontal second wall is added or being built as an additional support to bear the load above.

The existence of the mural could be noticed and viewed, only after being told; and only partially from the right end of the mural-wall. Absence of needed light to view the art in such a narrow space is understandable and obvious, except with the help of a torch light. Therefore to view and record the visual in full, in a normal manner is next to impossible, unless the frontal wall is totally pulled down or dismantled. A modest attempt to explore has become possible herein - only because there's been a very wise use of high-tech tools and gadgetry to digitally document it by the experts from Japan. And the digital record thus, enabled to read and explore, on the aspects like probable contents, style and the materials used in the mural. The second challenge but also equally important, is the physical state of the mural or the painting. The pictorial area occupies comparatively a small area of the wall - about less than two feet in height and about three feet in width (?). The wall as a whole is filled with damaged plasters - rendering the contents very hard to read and guess about the original or actual shape and form. The primary contents full of scratches - small to larger, too are intermittently found damaged by years of human ignorance, or made so in purpose is not known.

\section{Contents of the mural}

Contents, Style and the Materials Used Regardless of all the challenges however, a modest attempt is made to read the painting. Within the pictorial area, two human forms can be seen in the two 
opposing ends. In the left is a male - a dancing man, a muscularly human - with matted hairs and is almost naked. He has an animal - an elephant hides behind his shoulders. He is seen with two emblems - left hand holding a skull cup - usually described as filled with human blood and his right hand is seen holding a long staff - 'Trishul' or a trident fitted with two triangle banners. It's widely recognized as the iconic emblem of Lord Shiva. Also, like lord Shiva, he has a third eye over his forehead. More interestingly, he is seen sporting beards and wearing a garland of (in-completed) round objects, - a preliminary shape to provide details of human heads or skulls, later. In the right end, is a female form, apparently a goddess or an attendant, seen mounted on a bull. The bull has ornaments - befitting of a divine vehicle. The goddess is well embellished with precious jewels and ornaments. Her right hand is seen holding reins of the bull - along with a rosary. She has a skull cup in her left hand. A cursory look of the descriptions made above, may give an impression that two human forms represent Lord Shiva and his consort Parvati or Uma.

However, in a second look, it appears, some notable discrepancies are found - to make the conclusion. It is only reasonable therefore, to see it from other angles as well - like the time it was supposedly painted, preferred beliefs of the patron and of all, possible extant evidences to support the argument. Looking at the mural - firstly, from the 'Style' it's rendered, for sure, it's well consistent with the prevailing style of the late $16^{\text {th }}$ and $17^{\text {th }}$-century Newar paintings. And during $17^{\text {th }}$-century when the Palace was built to the present state,
King Pratap Malla was in the throne of Kathmandu. He passed away some time in $1674 \mathrm{CE}$. And as a lover of art and a follower of esoteric beliefs, the entire building is dedicated as a home to ancestral deities - that is Agam-Chhen. Accordingly, he had had great faith in the thoughts of 84 Maha-Siddhas, the great adepts or the sages.

The imagery, thus in our context, in all likelihood, represents one of the adepts - called 'Kapalika' - a follower of Lord Shiva. All the 84 Maha-Siddhas are illustrated usually attended by a female attendant. A folded master sketch book - believed to have been created - as had been ordered by the King himself, presently is in the collections of Los Angeles County Museum of Art (LACMA). Based on the features described on the adept or the Maha-Siddha stated above, many of the attributes seemed to follow and do coincide. However, there are also, some deviations from the sketch book.

But it appears, the King may had had made minor changes so as to depict the human forms as per his personal deep respects. As for example, unlike in the sketch book, the Siddha here has a third eye and the female attendant is shown mount on a bull. The change is made here maybe to provide the deities the divine status - much above a Tantric Siddha and an attendant. The extant details describe the artist of the master sketch book as certain - 'Citrakara Jugideva' or in a more Sanskritized form as Chitrakar Yogideva during 794 NS or correspondingly to 1674 CE. It's also quite likely, the same artist or his team may have been involved in the mural work. 


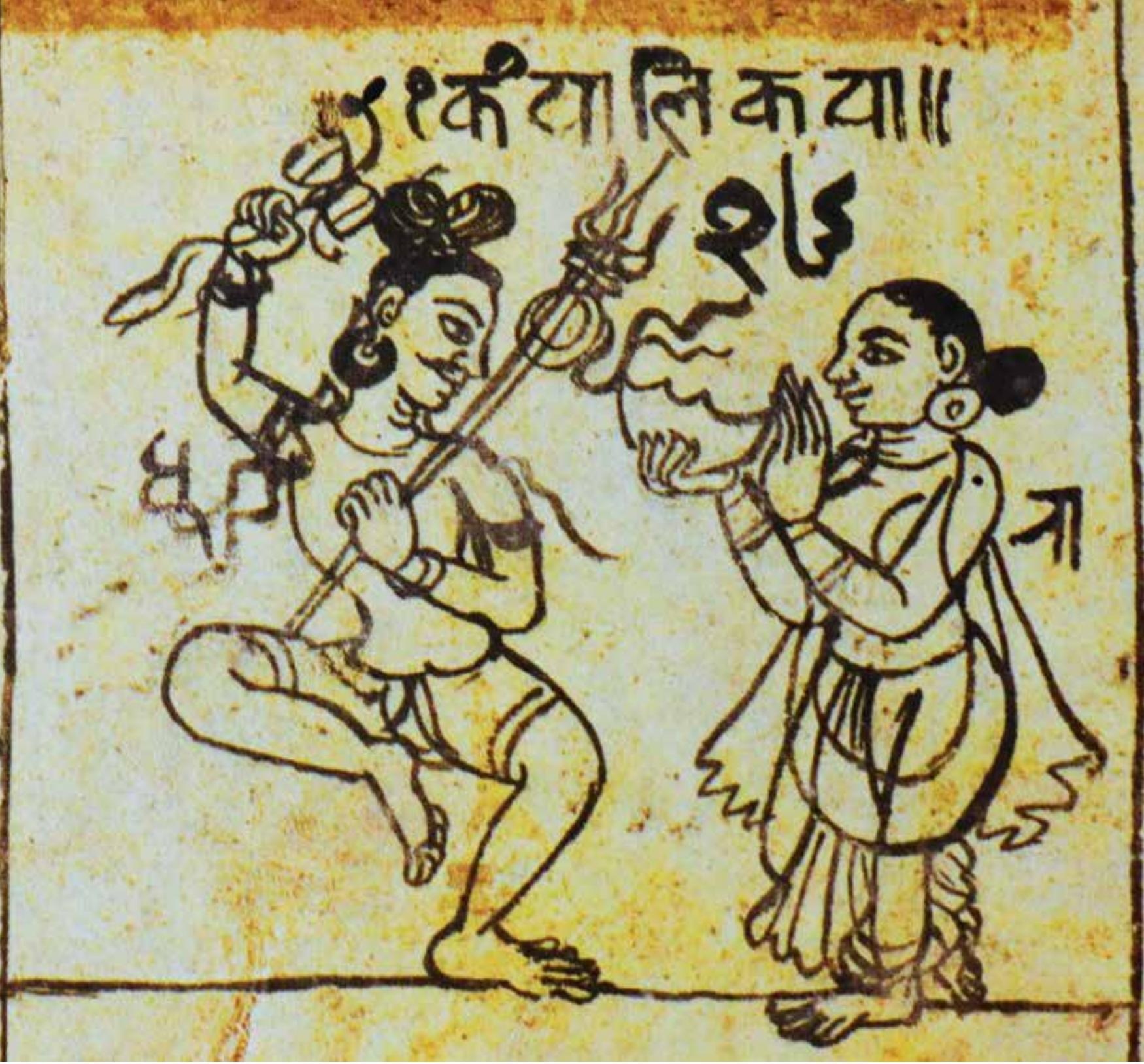

Kampalika - the key sketch of the adept, as found in the master sketch book. Collection of Los Angelos County Museum 


\section{Conclusion}

The mural, regardless of its present physical state, stands however as an important testimony of time - rise of the prevailing chosen beliefs, artistic style and the competitive spirit of the then Royals leading to create murals inside their respective Palace interiors, especially in the prayer places.

However, seen professionally and objectively, it's also likely the mural is an in-complete work. Many of the line drawings are yet to be filled with the due prescribed colors - as per the instructions made in the master book. While many of the colors used in the mural, apparently are derived from natural pigments of earth and minerals, there's also a liberal use of gold paints in the ornament works. Many of the ornaments are also left blank, suggesting the artist is made to leave the work, in a sudden haste. The notable lack of details in the garland worn by the Siddha, as stated in earlier lines, also indicates to this guess. A likely explanation could be the sudden demise of the patron who commissioned the work, King Pratap Malla himself.

Courtesy:

Investigation Report and Proposal of Rehabilitation Plan; for the Aganchen Temple and Associated Buildings, Hanuman Dhoka Durbar Square, Kathmandu

March 2020

Tokyo National Research Institute for Cultural Properties

\section{Reference Consulted}

Buhnemann, Gudrun. (2008). Buddhist Iconography and Ritual in Painting and Line Drawings From Nepal. Lumbini International Research Institute. P. $25,26,37$ 